\title{
Exploring the Effect of National Culture on Corporate Environmental Proactivity
}

\author{
Ilaria Tutore \\ University of Naples Parthenope, Italy
}

\begin{abstract}
The aim of the paper is to analyze if and in which way the national culture acts as a driver toward the implementation of corporate environmental strategy. An environmental proactive strategy seeks to reduce environmental impact and manage the interface between business and the nature beyond imposed compliance. It is recognized that the introduction of environmental protection can be used to develop successful strategy to reach a competitive advantage. The Organization and the natural environment literature identify several drivers able to push toward ecological engagement. One of the most important is the ethical attitude of organizations. Ethics could vary among different organizations because of different circumstance; in particular ethical values are strictly embedded to culture. The most of literature focused the analysis on the broader issue of Corporate Social Responsibility, analyzing the effect of national culture on Corporate Social Performance. Conversely, only few studies have analyzed the relationship that occurs between the national culture and the environmental proactivity, employing national environmental indicator rather than firms' performance scores. Previous studies, which used Hofstede's framework, have found out that the national culture is able to influence the overall national environmental performances, missing to analyze cultural impact on company's environmental behaviour. Does the national culture influence the company's attitude to implement a proactive environmental strategy? Which cultural dimension is able to represent this pressure? The study is based on a quantitative analysis aimed at statistically measuring how national culture could influence corporate environmental proactivity, measured using the CDP Global 500 report.
\end{abstract}

Keywords: Cross-cultural management, Environmental performance, National culture values, Organization and natural environment.

\section{Introduction}

The trade-off existing between the goals of achieving an high and sustainable economic growth and to keep an high environmental standard is nothing new.

At organization level, the environmental protection has become an important issue since pollution and natural resources' depletion represent a wide source of costs. Companies may play a significant role in the reduction of man activities' impact on natural environment also promoting a world more ecologically sustainable.

During the last years the Organization and Natural Environment (ONE) stream of research focused the attention on the linkage existing among environmental protection, business management and strategy. According to some researchers (Hass, 1996; Kolk and Mauser, 2002) this attitude can increase by the time, following an ideal path toward sustainability (Hunt and Auster, 1990; Roome, 1992; Hart, 1995; Ghobadian et al., 1998).

The proactive environmental strategy ideally represents the last stage of environmental effort into management practices (Hunt and Aster, 1990). It is defined as the one that seeks to reduce the environmental impact and to manage the interface between business and the nature beyond imposed compliance (Sharma, 2000; Aragon - Correa and Sharma, 2003).

It is characterised by the presence of four basic elements (Delmas et al., 2011): a environmental reporting; b operational improvements; c organisational changes; d regulatory proactivity. According to some researcher, the introduction of environmental protection at firm level could be used to develop successful strategy to reach a

International Journal of Operations Management, vol. 1, issue 5, pp. 17-22, October 2021 
competitive advantage. The reduction of inefficiencies and the rationalization in the use of natural resources are important sources of cost reduction, as the environmental attributes of products and services (Orsato, 2006; Porter and Van der Linde, 1995) are used for marketing differentiation.

Several researches rather have tried to identify, analyse and classify the drivers that may encourage a company to develop and sustain its environmental engagement. Environmental regulations and stakeholder pressure are considered the external drivers, while company's characteristics are the internal ones.

One of the most important factor able to affect company's environmental engagement and the implementation of environmental strategy is the level of ethical attitude.

Infact, in presence of a strong ethical motivations, related with the 'right thing to do' environmental protection become an important matter into organisations.

Ethics is related to values, strictly embedded with both national and organizational culture.

In particular, national culture has been defined as “ '...patterns, explicit and implicit, of and for behaviour acquired and transmitted by symbols, constituting the distinctive achievements of human groups" (Kroeber and Kluckhohn, 1952, p. 13).

The culture shapes the orientation of individuals to take sustainable initiatives and to translate these engagement at firm level.

The most of literature focuses on the effects of the cultural values on the broader issue of Corporate Social Responsibility (Ho et al., 2012; Parboteeah, 2012; Ringov and Zollo, 2007), only few studies have specifically analyzed the relationship that occurs between the national culture and the corporate environmental engagement. In particular, these studies (Park et al., 2007; Husted, 2005), employ national environmental indicators, without focus on this connection at organization level.

In order to cover the gap of existing literature, has been formulated the following research question:

RQ: Does the country's national culture affects the company's environmental proactivity? The paper is articulated as follows: the first section presents the theoretical background highlighting the main literature on the topic and it develops the hypotheses; section 2 describes the dataset and variables; section 3 presents the result of the analysis. Lastly, in the section 4 are presented the implications of results and the conclusions.

\section{Literature Review and Hypotheses}

Cross-cultural studies have analyzed the influence that national culture exerts on company's social responsibility from different viewpoints employing as their basis Hofstede's (Husted, 2005; Park et al., 2007; Ringov and Zollo, 2007; Ho et al., 2012) or GLOBE (Ringov and Zollo, 2007; Parboteeah et al., 2012) cultural dimensions.

Despite previous analysis used different models, they assumed that the different sets of values, beliefs, attitude and moral, rooted in the national culture drive individuals on their choices and actions. Therefore, national culture is strictly embedded at the corporate social or environmental behaviours and some cultural dimensions are more likely to support these initiatives than the others.

In order to understand how the national culture affects on the corporate environmental engagement and then their ability to implement a proactive environmental strategies, this paper considers Hofstede's cultural dimensions.

According to Hofstede, culture can be defined as "a collective programming of the mind which distinguishes one group from another" (Hofstede, 1980, p. 25).

From a deep survey to about 60,000 people from over 50 countries, he identified cultural values that distinguish countries from each others, grouping them into four clusters (even if other two dimensions has been added afterwards), called dimensions of national culture (Hofstede, 1980, 2001):

- $\quad$ Power Distance (PD): it refers to the tolerance of unequal distribution of power;

- $\quad$ Individualism/Collectivism (IDV): it expresses the degree of individuals to take care of themselves or to feel a part of a group and take care of its members.

- Masculinity/Femininity (MAS): it is related to individuals' concern of achievement, assertiveness, competition. On the other side, femininity into society is related to the focus of life's quality and interpersonal cooperation;

- $\quad$ Uncertainty Avoidance (UA): it is the extent to which individuals in nations tolerate ambiguity in their lives and are willing to take risks. 
Employing these cultural dimensions as their basis, previous research found out that in the presence of high level of Power Distance and Masculinty into society is linked to lower environmental performance (Park, Russel and Lee, 2007) and institutional capacity of a country for environmental sustainability (Husted, 2005). Regarding to Corporate Social Performance, Ringov and Zollo (2007) found out that in a presence of high Power Distance and Masculinity is related with lower CSP performance, while Ho et al. (2012) achieved opposite results.

The degree of Individualism into society has been hypothesized to be negatively related to environmental performance and overall responsibility behavior. Previous scholars were not agree about the effect of Uncertainty Avoidance on firms' environmental performance. According to Ringov and Zollo (2007) and Husted (2005), firms based in country with high level of risk avoidance should show lower environmental or sustainability performance in cause of the small willing to invest into innovative activity, often not related to computable returns.

Empirical results of such studies did not support this assumption. On the contrary, according to Park, Russel and Lee (2007), in presence of an high degree of Uncertainty Avoidance, firms try to find environmental solutions, as individuals feel threatened by uncontrollable risk posed by nature. They should put greater effort to reduce these risks than individuals from low risk avoidance countries do. Also in this case, any empirical result has been found. Also Ho et al. (2012) showed that countries with higher UA exhibit higher corporate social performance.

Considering the previous researches the following hypotheses have been formulated:

H1: the firms based in higher Power Distance countries show a worsen level of environmental performance

H2: The firms based in Individualistic countries show a worsen level of environmental performance

H3: The firms based in Masculine countries show a worsen level of environmental performance

H4: The firms based in higher Uncertainty Avoidance countries show an higher level of environmental performance Despite the existing studies did not do this, the paper also considers the fifth Hofstede's cultural dimension, namely the Long Term Orientation, initially called Confucian dynamism. It refers to individual's propensity to save for the future and his ability to change tradition to changing conditions. For this reason is reasonable to think that in a presence of high level of LTO, individuals try to consider environmental engagement as an important matters.

Then the last hypothesis is:

H5: The firms based in a country featured with an high level of Long Term orientation, show an higher level of environmental performance

\section{Data And Measures}

\subsection{Dependent Variable}

The analysis is concentrated on the evaluation of national cultural's effect on environmental practivity rather than environmental performance. Considering the complexity of the definition of environmental proactivity, to find an effective indicator able to measure it is not an easy task. Christimann (2000) has already revealed that data on firms' environmental practices and the cost reduction due to the implementation of green practices are not avaible from public and global database. Previous ONE's research used qualitative measures based on mail surveys of a specific samples companies, environmental indicators provided by institutional agencies; some other used the presence of EMS as a measures of proactivity. Consistent with the definition provided by Delmas et al. (2011), the measure of environmental disclosure is considered a proxy of environmental proactivity. For this reason, the paper employs as dependent variable the company's carbon disclosure score (CDS), measured by Carbon discosure project (CDP). Every year, CDP asks to the Global 500 companies to measure and report what climate change means for their business. During the $2011,81 \%$ (404) of corporations answered to the CDP questionnaire. A score (from 0 to 100) is applied to most of the company responses to CDP, which are assessed for disclosure and performance. Low CDS $(<50)$ indicates limited or restricted ability to measure and disclose risks and opportunities that came from carbon emissions. The companies which gain this score show a compliance attitude towards environmental -or more precisely carbon- problems. It does not indicate poor performance but a low score is assigned to companies that provide insufficient information to evaluate performance and could be considered inactive to climate change. Vice-versa high CDS ( $>70)$ indicates a more deep involvement into climate change issue: companies identify into climate change management a tool to reach a strategic advantage. In this companies "senior management understand the business issues related to climate change and are building climate related risks and opportunities into core business" (CDP, 2011, p. 22). Moreover, the carbon disclosure project grouped all companies with the highest disclosure score (more than 50) with a performance bands:A, A-, B, C, D and E. All the score and bands simply recognize the evidence in action. 


\subsection{Explanatory Variables}

This research focalizes the attention on the role of national culture into shape company's environmental engagement. Considering the most of literature, 5 different cultural dimension developed by Hofstede (1980) are employed:

- $\quad$ Power Distance (PD)

- $\quad$ Individualism (IND)

- $\quad$ Uncertainty Avoidance (UA)

- $\quad$ Masculinity (MAS)

- $\quad$ Long-term Orientation (LTO)

\subsection{Control Variables}

In order to confirm the relationship between national cultural dimension and company's environmental proactivity, control variables which could have a strong impact on company's environmental engagement are introduced. The selected three variables had been identified by the extant literature as relevant drivers for firms' environmental proactivity. These are: company's revenues as proxies of firm's dimension (Benito and Benito, 2006); company's age (Hass, 1996; Kolk and Mauser, 2002), as usually environmental orientation increases by the time and R\&D expenditures. Data have been collected from Businessweek (2011).

\subsection{Analysis}

To test the hypotheses it is used IBM SPSS Statistic software. The raw sample included 500 companies contacted by CDP report. A screen of the sample has been then developed, in order to evaluate the presence and the availability of the necessary data. The final sample includes only those companies that responded to CDP's questionnaire and that distinctly belong to a specific country. Final sample is then composed by 368 companies from 30 different countries 1 and operated in 9 different industries (See Table 1).

Table 1: Industry composition of the final sample

\begin{tabular}{|l|c|c|c|}
\hline & Frequency & $\mathbf{\%}$ & Cumulative \% \\
\hline CONSUMER & 44 & 12,0 & 12,0 \\
DISCRETIONARY & 38 & 10,3 & 22,3 \\
ENERGY & 84 & 22,8 & 45,1 \\
FINANCIAL & 29 & 7,9 & 53,0 \\
HEALTH CARE & 37 & 10,1 & 63,0 \\
INDUSTRIAL & 29 & 7,9 & 70,9 \\
INFORMATION & 37 & 10,1 & 81,0 \\
TECHNOLOGY & 18 & 4,9 & 85,9 \\
MATERIALS & 29 & 7,9 & 93,8 \\
UTILITIES & 23 & 6,3 & 100,0 \\
CONSUMER & 368 & 100,0 & \\
STAPLES & & & \\
NOT SPECIFIED & &
\end{tabular}


Ilaria Tutore

Exploring the Effect of National Culture on Corporate Environmental Proactivity

The ANOVA reveals no differences among national cultural dimension in different industries (Table 2). Conversely, ANOVA reveals a significant effect of industry on $\operatorname{CDS}(\mathrm{F}=1,699 ; \mathrm{p}$ - value $<, 10)$, Revenues $(\mathrm{F}=3,266 ;<, 01) ; \mathrm{R} \& \mathrm{D}$ expenditure $(\mathrm{F}=4,619 ; \mathrm{p}$-value $<, 01)$, and Longevity $(\mathrm{F}=4,885 ; \mathrm{p}$-value $<, 01)$,

Table 2: ANOVA's results

\begin{tabular}{|c|c|c|c|c|c|}
\hline Dimension & $\begin{array}{l}\text { Sum of } \\
\text { squares }\end{array}$ & Df & $\begin{array}{c}\text { Mean } \\
\text { square }\end{array}$ & $\boldsymbol{F}$ & P-Value \\
\hline \multicolumn{6}{|l|}{$P D$} \\
\hline Between groups & 2642,862 & 9 & 293,651 & 1,027 & ,418 \\
\hline Within groups & 102359,214 & 358 & 285,920 & & \\
\hline Total & 105002,076 & 367 & & & \\
\hline \multicolumn{6}{|l|}{$I N D$} \\
\hline Between groups & 4458,417 & 9 & 495,380 & 0,781 & ,634 \\
\hline Within groups & 227178,059 & 358 & 634,576 & & \\
\hline Total & 231636,476 & 367 & & & \\
\hline \multicolumn{6}{|l|}{$U A$} \\
\hline Between groups & 1834,195 & 9 & 203,799 & 0,771 & ,644 \\
\hline Within groups & 94657,240 & 358 & 264,406 & & \\
\hline Total & 96491,435 & 367 & & & \\
\hline \multicolumn{6}{|l|}{$M A S C$} \\
\hline Between groups & 3178,509 & 9 & 353,168 &, 851 &, 569 \\
\hline Within groups & 148485,010 & 358 & 414,763 & & \\
\hline Total & 151663,519 & 367 & & & \\
\hline \multicolumn{6}{|l|}{ LTO } \\
\hline Between groups & 6531,724 & 9 & 725,747 & 1,167 & ,315 \\
\hline Within groups & 222681,752 & 358 & 622,016 & & \\
\hline Total & 229213,476 & 367 & & & \\
\hline \multicolumn{6}{|l|}{$C D S$} \\
\hline Between groups & 5013,717 & 9 & 557,080 & 1,669 &, $095^{*}$ \\
\hline Within groups & 119491,324 & 358 & 333,775 & & \\
\hline Total & 124505,041 & 367 & & & \\
\hline \multicolumn{6}{|l|}{ REVENUES 2011} \\
\hline Between groups & $7,3559 \mathrm{E}+22$ & 9 & $8,173 \mathrm{E}+21$ & 3,266 &, $001 * * *$ \\
\hline Within groups & $8,959 \mathrm{E}+23$ & 358 & $2,503 \mathrm{E}+21$ & & \\
\hline Total & $9,6946 \mathrm{E}+23$ & 367 & & & \\
\hline \multicolumn{6}{|l|}{ LONGEVITY } \\
\hline Between groups & 122382,619 & 9 & 13598,069 & 4,885 &, $000^{* * *}$ \\
\hline Within groups & 996446,588 & 358 & 2783,370 & & \\
\hline Total & 1118829,207 & 367 & & & \\
\hline \multicolumn{6}{|l|}{$R \& D 2011$} \\
\hline Between groups & $1,6847 \mathrm{E}+20$ & 7 & $2,407 \mathrm{E}+19$ & 4,619 &, $000 * * *$ \\
\hline Within groups & $4,5854 \mathrm{E}+20$ & 88 & $5,211 \mathrm{E}+18$ & & \\
\hline Total & $6,2701 \mathrm{E}+20$ & 95 & & & \\
\hline
\end{tabular}

Then, the bivariate correlation among variables is calculated (Table 3). As many cross- cultural studies have highlighted, the cultural dimensions are highly correlated each others. The Carbon disclosure score is positively correlated with the level of Uncertainty Avoidance $(0,198$, p-value $<0,01)$, firm size $(0,140$; p-value $<0,01)$, company's longevity $(0,129 ; \mathrm{p}$ - value $<0,05)$ and $R \& D$ expenditures $(0,293$; p-value $<0,01)$.

Table 3: Correlations and descriptive statistics

\begin{tabular}{|lccccccccccc|}
\hline & Mean & SD & (1) & (2) & (3) & (4) & (5) & (6) & (7) & (8) & (9) \\
\hline (1) PD & 49,10 & 16,91 & 1,00 &,$- 753^{* *}$ &,$- 139^{* *}$ &, $318^{* *}$ &, $321^{* *}$ & 0,06 & 0,05 & $-0,04$ & 0,13
\end{tabular}


Ilaria Tutore

Exploring the Effect of National Culture on Corporate Environmental Proactivity

\begin{tabular}{|c|c|c|c|c|c|c|c|c|c|c|}
\hline (2) IND & 68,74 & 25,12 & 1,00 &, $138^{* *}$ &,$- 333^{* *}$ &,$- 526^{* *}$ & $-0,07$ & $-0,06$ & 0,05 & $-0,16$ \\
\hline (3) $\mathrm{UA}$ & 58,32 & 16,21 & & 1,00 &, $134^{* *}$ &, $281^{* *}$ &, $198^{* *}$ & 0,03 & $-0,04$ & $-0,05$ \\
\hline (4) MASC & 55,18 & 20,33 & & & 1,00 &, $111^{*}$ & 0,03 & $-0,01$ & $-0,09$ & $-0,01$ \\
\hline (5) LTO & 38,24 & 24,99 & & & & 1,00 & 0,09 & 0,02 & 0,02 & 0,04 \\
\hline (6) CDS & 69,59 & 18,42 & & & & & 1,00 &, $140^{* *}$ &, $129^{*}$ &, $293^{* *}$ \\
\hline (7) SIZE (MIL \$) & 39300,94 & 51396,40 & & & & & & 1,00 & 0,08 &, $520^{* *}$ \\
\hline (8) LONG & 82,14 & 55,21 & & & & & & & 1,00 & 0,13 \\
\hline (9) R\&D (MIL \$) & 2340,81 & 2569,07 & & & & & & & & 1,00 \\
\hline
\end{tabular}

The further step of the analysis consisted of two regression functions (Table 4): the first model considers the impact of control variables on Carbon Disclosure Score, in the second model the cultural dimensions are inserted.

Table 4: Regression results

\begin{tabular}{|c|c|c|}
\hline & \multicolumn{2}{|c|}{ Model } \\
\hline Variable & 1 & 2 \\
\hline \multicolumn{3}{|c|}{ Hofstede cultural dimensions } \\
\hline \multirow[t]{2}{*}{ Power Distance } & & $-0,113$ \\
\hline & & $(0,183)$ \\
\hline \multirow[t]{2}{*}{ Individualism } & & $-0,16$ \\
\hline & & $(0,154)$ \\
\hline \multirow[t]{2}{*}{ Uncertainty Avoidance } & & $0,318 *$ \\
\hline & & $(0,161)$ \\
\hline \multirow[t]{2}{*}{ Masculinity } & & $-0,01$ \\
\hline & & $(0,110)$ \\
\hline \multirow[t]{2}{*}{ Long-term Orientation } & & $-0,02$ \\
\hline & & $(0,121)$ \\
\hline \multirow[t]{2}{*}{ Size } & $1,011 \mathrm{E}-10$ & $6,727 \mathrm{E}-11$ \\
\hline & $(6,894 \mathrm{E}-11)$ & $(7,072 \mathrm{E}-11)$ \\
\hline \multirow[t]{2}{*}{ Longevity } &, 043 & 0,056974708 \\
\hline & $(0,40)$ & $(0,042)$ \\
\hline \multirow[t]{2}{*}{$\mathrm{R} \& \mathrm{D}$} & $1,485 \mathrm{E}-09^{*}$ & $1,654 \mathrm{E}-09 *$ \\
\hline & $(8,931 \mathrm{E}-10)$ & $(8,927 \mathrm{E}-10)$ \\
\hline \multirow[t]{2}{*}{ Constant } & $60,168 * * *$ & $59,556 * * *$ \\
\hline & $(4,090)$ & $(22,301)$ \\
\hline Observations & 368 & 368 \\
\hline R-Squared & 0,121 & 0,190 \\
\hline F-Statistics & $4,202 * * *$ & $2,553 * *$ \\
\hline
\end{tabular}

Regression results of model 1 show that the level of R\&D is the only variable significantly related to Carbon Performance Score. In model 2, where cultural measures are introduced, the significance of the analysis increases (Rsquare $=0,190$ ). It means that cultural dimensions exert an important effect on the level of environmental proactivity. 
In particular, the level of Uncertainty Avoidance has a significant positive impact on Carbon performance Score, finding support for H3. Despite the sign among variables is consistent with the assumptions, hypotheses H1, H2, H4 cannot be confirmed, due the poor significance of the predictors. Long Term Orientation is rather negatively related to CDS, again $\mathrm{H} 5$ cannot be confirmed in cause of the poor significance.

\section{Discussion and Conclusion}

Nowadays, environmental problems are receiving more and more attention at firm level. The snvironmental proactivity is considered an important tool for gain a competitive advantage, helping to reduce costs or increase differentiation. Both theorist and practitioners highlight that national culture is an important drivers toward this proactivity, as the set of values and beliefs could affect company's ethical - or more specific, environmental- choices and actions. Starting from this consideration, the paper analyzed the effect of cultural dimension, using the framework provided by Hofstede (1980), on corporate environmental proactivity. Despite the linkage among variables follow the developed hypothesis, just the H3 had found statistical support. In particular, it is demonstrated that companies based in a country that have difficult to deals with the fact that future can never be known, try to control it by implementing a more effective environmental practices. People do not feel comfortable in ambiguous situation and try to create beliefs and institutions that try to avoid this uncertainly. Therefore, the study presents some remarkable implication but also basic limitations. From a theoretical point of view, it opens the mind to deep analyze the predicted relationship among variables, since different results are presented. From a managerial standpoint, the study of the cross-cultural differences could affect the effectiveness of environmental practices at both intra and inter organization levels. The lack of environmental indicator to measure corporate environmental proactivity is the main limitation. The lack of synthetic measure of practivity can be the cause of different outcomes within these researches. Moreover, some important point is still missing. Even if it is demonstrated that national culture exerts a particular role into shaping environmental engagement, studies on this topic only examines the sinlge effect of different cultural dimension on proactivity. Different results could derive as there exists a combined effect of cultural variables to be explored in depth, that could represent a new and interesting research issue.

\section{Bibliography}

1. Aragon-Correa, J. A. and Sharma, S. (2003). A contingent resource based view of proactive corporate environmental strategy. Academy of Management Review, 29(1), 71-88. Crossref

2. Benito, J. C. and Benito, O. C. (2006). A Review Of Determinant Factors Of Environmental Proactivity. Business Strategy and the Environment, 15(2), 87-102.

3. Carbon Disclosure Project. (2011). CDP Global 500 Report 2011, Accelerating Low Carbon Growt. Retrieved from https://www.cdproject.net/CDPResults/CDP-G500-2011- Report.pdf.

4. Christmann, P. (2000). Effects of "Best Practices" of Environmental Management on Cost Advantage: The role of Complementary Assets. Academy of Management Journal, 43(4), 663-680. Crossref

5. Delmas, M. A., Hoffmann, V. H. and Kuss, M. (2011). Under the Tip of the Iceberg: Absorptive Capacity, Environmental Strategy and Competitive Advantage. Business \& Society, 50(1), 116-154.

6. Ghobadian, A., Viney, H., Liu, J. and James, P. (1998). Extending linear approaches to mapping corporate environmental behavior. Business Strategy and the Environment, 7(1), 13-23. Crossref

7. Hart, S. L. (1995). A natural resource based view of the firm. Academy of Management Review, 20(4), 986-1014.

8. Hass, J. L. (1996). Environmental (green) management typologies: an evaluation, operationalization and empirical development. Business Strategy and the Environment, 5(2), 59-68.

9. Ho, F. N., Wang, H. D. and Vitell, S. J. (2012). A Global Analysis of Corporate Social Performance: The Effects of Cultural and Geographic Environments. Journal of Business Ethics, 107(4), 423-433. Crossref

10. Hofstede, G. (1980). Culture Consequences: International Differences in Work-related Values. London: Sage Publications.

11. Hofstede, G. (2001). Culture's Consequences. Comparing values, behaviors, institutions and organizations across nations (2nd ed.). Thousand Oaks (CA): Sage. 
12. Hunt, C. B. and Auster, E. R. (1990). Pro-active environmental management: avoiding the toxic trap. Sloan Management Review, (31)2, 7-18

13. Husted, B. W. (2005). Culture and ecology: a cross-national study of the determinants of environmental sustainability. Management International Review, 45(3), 359-371.

14. Kolk, A., and Mauser, A. (2002). The Evolution of Environmental Management: From Stage Models to Performance Evaluation. Business Strategy and the Environment, 11, 14-31. Crossref

15. Kroeber, A. L. and Kluckhohn, C. (1952). Culture: A critical review of concepts and definitions. Peabody Museum Papers, 42, 12-22.

16. Orsato, R. (2006). Competitive environmental Strategies: when does it pay to be green?.

17. California Management Review, 48(2), 127-143.

18. Parboteeah, P. K., Addar, H. M. and Cullen, J. B. (2012). Propensity to Support Sustainability Initiatives: A Cross-National Model. Journal of Business Ethics, 105(3), 403-413. Crossref

19. Park, H., Russell, C. and Lee, L. (2007). National culture and environmental sustainability a cross-national analysis. Journal of Economics and Finance, 31(1), 104- 121.

20. Paulraj, A. (2009). Environmental motivations: a classification scheme and its impact on environmental strategies and practices. Business Strategy and the Environment, 18(7), 453-468.

21. Porter, M. E. and Van Der Linde, C. (1995). Green and competitive: ending the stalemate. Harvard Business Review, 73(5), 120-134. Crossref

22. Ringov, D. and Zollo, M. (2007). Corporate responsibility from a socio-institutional perspective: the impact of national culture on corporate social performance. Corporate Governance,7(4), 476-485.

23. Roome, N. (1992). Developing Environmental Management Strategies. Business Strategy And The Environment, 1(1), 11-24. Crossref 